\title{
Why Business Intelligence Is the New Oil for the Upcoming Enterprise
}

\author{
Azza Qais Abdullah Al Anasri \\ Saja Mohamed Murad Al \\ Balushi \\ Jitendra Pandey
}

\author{
MIDDLE EAST COLLEGE \\ Middle East College \\ Middle East College
}

Much has been said about data being the new oil that will fuel businesses in the future. But the reality is that it's not about the amount of data that organizations have access to, but how effective their decisions are based on that data. Therefore, data alone will not be the new oil, rather intelligence will fuel the digital economy, and organizations that can create intelligent business processes to deliver contextualized and consent-based experiences will win in this new data-driven world. As intelligence (and technology in general) increasingly underpins future business models, there is a big question around the role of IT moving forward. The CIO needs to be part of boardroom discussions driving decision-making around the broader business (and digital) strategy. This raises yet another debate about the role of the CIO in this context. In parallel, there is clearly an emerging role in a digital platform architecture to drive "moments of truth" into these intelligent business processes. The next phase of the application landscape evolution is going to all be about integration, and IDC believes that integration and extension capabilities are critical to drive the business-process orchestration strategy enabling future business processes. This platform will provide a unified set of connection points across multiple systems' applications and digital apps that might be distributed across on-premises, hosted, or public clouds. Based on these capabilities, the digital platform can be used to fast-track integration and trigger new workflows/business processes, leveraging applications that could be a mix of legacy on-premises and SaaS applications.

The proposed research focusses on how Knowledge Management and Business Intelligence could potentially play out in many futuristic organizations.

\section{Introduction}

Business Intelligence is an innovative approach in the modern corporate world which businesses, companies, organization and individuals are using for being more competitive in the market and respective sectors. It consists of such architectures, technologies and processes which analyze the raw data into such meaningful format, which helps the organization to use it for decision making and increasing their profit figures. Various tools in this architecture perform the actions which are in the greater interest of the organizations. These tools perform the multiple functions for organizations such as reports creation, dashboards, graphs, summaries, charts, and maps, which provide the business reasonable understanding to assess the market factors and utilize that information for the overall benefit of the organizations. The primary purpose of using business intelligence tools is to improve the decision making of businesses. It combines various fields such as business analytics, data visualization, infrastructure, data mining, and data tools so that to help the business sector organizations to integrate data-driven decision-making structure in their operational network. This sector of business intelligence has evolved many other processes and activities so that to improve the performance. This process includes data mining, which uses databases, machine learning and statistics. Reporting, benchmarking and performance metrics are also the means to improve the decision-making structure. Descriptive statistics, querying and statistical analysis are the processes that are part of the business intelligence structure along with 


\section{Journal of Student Research}

Fourth Middle East College Student Research Conference, Muscat, Sultanate of Oman

data visualization, visual analysis, and data preparation. So basically, this process is a technology riven that analyzes the data and presents into such actionable formation, which helps management executive and corporate gurus in the organization to improve their decision making. There is a large set of tools, applications and methodologies which are used for this purpose. (Babu, 2012).

Business Intelligence application in the business world is much more extensive as it impacts on the business operation, tactical and strategical decision making. Historical data is used in this process instead of gut feeling and assumptions. Companies can use business intelligence tools in a variety of ways to gain a competitive advantage in the market. It helps companies to enhance that quality and decision-making quality by benchmarking the varied processes. The unique feature of the business intelligence tools is that it provides a view of the business operation regarding historical as well as current and predictive. These tools application is not confined to big firms, but small and medium level enterprises can also use it for their organizational benefits. Business intelligence benefits for the business sector are far-reaching and useful on a variety of aspects. It leverages the business by improving their performance through applying effective and efficient techniques with the help of information which is presented by these business process tools. Business intelligence makes the corporate sector organization smarter, and their decision making becomes more data driven. These factors help the companies to identify the various way through which they can increase their profit as well as customer behavior is also analyzed more constructively. The performance of the company is tracked by benchmarking it with the competitor in the market. It helps the companies to optimize their operation and predicting factors that can help them to be more successful in the competitive business market. It allows companies to identify the grey areas which can be improved to be more competitive in the business world and spotting marketing trends. This provides valuable insight into the market information and identifies the ways through which these opportunities can be capitalized more positively. Business intelligence is a real blessing for the business world, and companies are using it to achieve their organizational goals constructively. (Loshin, 2012).

Figure 1. The role of Business intelligence in Knowledge Sharing

\section{Related Researches - Case Studies}

Customer relationship management (CRM) is software which is commonly used by the organization for the purpose of business intelligence. CRM provides benefits to the organization regarding tracking the interests of customers, their likes, and dislikes and to bring amendments in the product accordingly. Managing relationship is very important for the organization and they are required to model hem according to customers demand. CRM software provides an approach to manage relationship with customers with potential and current customers. Data analysis is done to analyze the history of the customers with company in order to improve the products and main focus is on the retention of the customers and sales growth. APPLE has introduced its application, where customers have their login ID and credential(Lauterbach and Bonime-Blanc, 2016). This APPLE application synchronizes all the devices with the CRM of the organization and predict the customer's choice on the basis of their interest. If greater number of the customer purchases specific product of the APPLE, the company focuses on that product on its products and thus prevent it from product of such product which is not commonly purchased. It helps the organization to save finance, money, and work force. It makes recommendations on the basis of what is being watched and played by the company. Database is created in CRM system and provides constant updating and evolving of its data regarding its all of customers in order to make particular target market.

\subsection{Maximizing operational efficiency by using NetSuite system by Coca-Cola}




\section{Journal of Student Research}

Fourth Middle East College Student Research Conference, Muscat, Sultanate of Oman

Coca is the largest beverages company which is independent partner of bottling. It has various customers at international level and around the world. Initially Coca-Cola was using manual reporting which makes it very difficult for the organization to get access to the number of its real time sales at different locations across the world and also regarding its operational data. Business intelligence team of the Coca-Cola handles of its reporting by using NetSuite System all the deliver operations are managed by this software to provide ease in the business and sequence in the management of data(West, Clifford and Atkinson, 2018). Business intelligence platform is used by the tea, to provide automation in the manual reporting procedures which saves almost 260 years each year which is a big benefit achieved by the organization and about forty hours each week. This states that business intelligence provide efficiency in the operation as compared to the manual tasks. Along with the automation of the report, coca cola also uses business intelligence applications for the integrations of its customer relationship management data with the help of mobile dashboards which provides such information which is actionable, time efficient and provides competitive advantage. In a business world, business intelligence platform provide efficiency in the performance and help the organization to attain profit thus competitive advantage. Through selfservice business intelligence Coca-Cola gets itself collaborated with business users and information technology which increases the expertise of the employees. Due to this analysts and IT employees of the Coca-Cola are capable of focusing on bigger strategy which can also help organization reach the success level and focus on long term innovations. So, the case study shows business intelligence as shifted manual working into automatic working.

\subsection{Business intelligence used by Google Analytics}

Google is one of the famous search engines commonly used by the people all around the world. It has greater number of users. In order to provide the user best browsing facilities there are different business intelligence software which are linked with the directory of the Google search engine by google Incorporation. Whenever any user searches a particular key word, its business intelligence analyzes the big data and uses different algorithm to know about the interests of the users and on the basis of that future recommendations are provided to the users of the system. This increases the reliability of the system and Google tries to focus on such things which are demanded by the users. Here the google Ads also plays a role. Google ads are used by different types of companies to have a promotion of their business, so when a user searched a particular product or thing, google provides its ads which also increases its business(Lauterbach and Bonime-Blanc, 2016). Therefore, many of companies used google ads for their promotional content in order to attract new customers. By doing this, employees working in the Google does not have search manually where to show the particular google Ad. It increases efficiency of the Google Inc and helped the organization to generate revenue. SAP is business intelligence tool, which provides various different solutions of data analytics on the basis of real time business intelligence using machine learning approaches.

\section{Problems}

There are various issues in the implementation of Business Intelligence. Once of the major issue is that BI Is Costly to implement. Spending plans and assets have always been tight, particularly for small businesses. Another challenge is the absence of Execution and Training. Absence of BI Impact (Low Use) as many organizations who have KM systems don't take up the BI seriously.

Unstructured Data of Business Intelligence and Deployment and Installation is another big challenge..

\section{Proposed Framework}

Out of the box business intelligence tools is the most reasonable approach for the new organization to implement business intelligence. This can be enough for many of the businesses. Before taking decision to use BI, it is important for an organization to make careful observations and 
understandings of its departments and implement BI where it is mostly required(Luhn, 2010). Organization will require systems for the implementation of the BI, and it is required to train the employees regarding how to use it. Because IT aspects can also bring vulnerabilities in the system.

Figure 2. Proposed KMBI Framework

Figure 3. BI Implementation Steps

Figure 4. Link Between KM and BI

\section{Business intelligence implementation steps}

\section{Design}

Figure 5. Importance of KMBI in Organizations

\section{Summary}

The report has provided information regarding the business intelligence. Business intelligence is considered as a new filed in the market which is grabbing attention of everyone in a business field. Business intelligence is linked with big data. Now a day's data is given a significant importance whether it is related to customers, employees of the organization, production of the products and services and other business information. By analyzing the data organization gain many unforeseen benefits which one might cannot predict or think about. Business intelligence has provided a way to an organization regarding how to use any type of data in an effective manner(Saxena and Srinivasan, 2013). It is an innovative approach to provide various types of benefits to the organization regarding increasing business performance, profit, success level and competitive advantage through various different ways. The architecture of BI is based on the technology and it analyses the raw data into meaningful information. The report has provided information regarding the steps which are used to implement BI in an organization.

If an organization want to retain its market position whether it's already success or close to success, BI is important factor for it. Also, any organization which is new in the field of business, it can also generate it maximum revenue by putting emphasis on the use of BI. There are different real time examples where companies are suing business intelligence, if one open up the business report of any successful company at national and international level, there he will get to know that reason behind the success is played by BI. Now everywhere there is boom of IT so for that BI is important. The report has analyzed case studies of Apple Inc, Google In and Coca-Cola.

\section{Conclusion}

From conclusion above, business intelligence plays a significant role in organization success. Its main usage is to help the employees, managers, and top management along with many operational workers to make a better decision for organization in case of any certainty or uncertainty. Organization get capable with all type of data all time. By doing this organization can ultimately grab many opportunities, can save time, cut cost, and can speed of inefficient systems(Shariat and Hightower Jr, 2007). Case studies provides a way to any organization which is thinking to 


\section{Journal of Student Research}

Fourth Middle East College Student Research Conference, Muscat, Sultanate of Oman

implemented BI and is confuse with the decision whether to use BI or not. So, the case studies provide help that there are different ways where business intelligence can be applied, Apple is using to manage relationship with customers, Coca-Cola is using to manage its sales at different locations while Google is suing for promotion of businesses. Data is presented and analyzed by the $\mathrm{BI}$ in the form an intelligent way where organization can be effective decision which can be turning point for the future of the organization. Actionable insights are extracted by BI with the helpful of algorithm which provides valid information, the data extracted can be in the form of descriptive analyses such as in the form of charts or graphs or ratios.

There are many benefits that have been analyzed in the report, but all are under one umbrella which is related to providing strength and power to the organization. Power of knowledge in the form of data is used. It helps the organization to understand the perspectives of the customers in an effective, providing personalized services to the customers in an easiest way, grading the leads of products, driving performance for the organization, and generating revenue, identification of trends in sales and improving efficiency of the operations.

\section{References}

Babu, K. V. S. N. (2012). Business intelligence: Concepts, components, techniques and benefits. Components, Techniques and Benefits (September 22, 2012).

Laursen, G. H., \& Thorlund, J. (2016). Business analytics for managers: Taking business intelligence beyond reporting. John Wiley \& Sons.

Larson, D., \& Chang, V. (2016). A review and future direction of agile, business intelligence, analytics and data science. International Journal of Information Management, 36(5), 700-710.

Loshin, D. (2012). Business intelligence: the savvy manager's guide. Newnes.

Lauterbach, A. and Bonime-Blanc, A. (2016) 'Artificial Intelligence : A Strategic Business And Governance Imperative', NACD Directorship.

Luhn, H. P. (2010) 'A Business Intelligence System', IBM Journal of Research and Development. doi: $10.1147 /$ rd.24.0314.

Saxena, R. and Srinivasan, A. (2013) 'Business intelligence', in International Series in Operations Research and Management Science. doi: 10.1007/978-1-4614-6080-0_7.

Shariat, M. and Hightower Jr, R. (2007) 'Conceptualizing business intelligence architecture.', Marketing Management Journal.

West, A., Clifford, J. and Atkinson, D. (2018) '“Alexa, build me a brand” An Investigation into the impact of Artificial Intelligence on Branding', The Business and Management Review.

Antoniadis, I., Tsiakiris, T. and Tsopogloy, S. (2015) 'Business Intelligence During Times of Crisis: Adoption and Usage of ERP Systems by SMEs', Procedia - Social and Behavioral Sciences. doi: 10.1016/j.sbspro.2015.01.1204.

Bernardino, J. and Tereso, M. (2013) 'Business intelligence tools', in Intelligent Systems, Control and Automation: Science and Engineering. doi: 10.1007/978-94-007-4722-7_25.

Bouma, J. et al. (2011) 'The Role of Knowledge When Studying Innovation and the Associated Wicked Sustainability Problems in Agriculture', Advances in Agronomy. doi:

10.1016/B978-0-12-386473-4.00011-7. 


\section{Journal of Student Research}

Fourth Middle East College Student Research Conference, Muscat, Sultanate of Oman

Chaudhuri, S., Dayal, U. and Narasayya, V. (2011) 'An overview of business intelligence technology', Communications of the ACM. doi: 10.1145/1978542.1978562.

Earley, P. C. and Mosakowski, E. (2004) 'Cultural intelligence', Harvard Business Review. doi: $10.1177 / 1470595808091787$.

Elbashir, M. Z. et al. (2013) 'Enhancing the business value of business intelligence: The role of shared knowledge and assimilation', Journal of Information Systems. doi: 10.2308/isys-50563.

Emam, A. Z. (2013) 'Critical success factors model for buisness intelligent over ERP cloud', in 2013 International Conference on IT Convergence and Security, ICITCS 2013. doi:

10.1109/ICITCS.2013.6717819.

Golfarelli, M., Rizzi, S. and Cella, I. (2004) 'Beyond data warehousing: What's next in business intelligence?', in DOLAP: Proceedings of the ACM International Workshop on Data Warehousing and OLAP.

Kaya, M. and Alhajj, R. (2006) 'Utilizing genetic algorithms to optimize membership functions for fuzzy weighted association rules mining', Applied Intelligence. doi: 10.1007/s10489-006-6925-0.

Lauterbach, A. and Bonime-Blanc, A. (2016) 'Artificial Intelligence : A Strategic Business And Governance Imperative', NACD Directorship.

Lim, L. K. S. (2013) 'Mapping competitive prediction capability: Construct conceptualization and performance payoffs', Journal of Business Research. doi: 10.1016/j.jbusres.2012.09.021.

Luhn, H. P. (2010) 'A Business Intelligence System', IBM Journal of Research and Development. doi: $10.1147 /$ rd.24.0314.

Pirttimaki, V. H. (2007) 'Conceptual analysis of business intelligence', SA Journal of Information Management. doi: 10.4102/sajim.v9i2.24.

Ranjan, J. (2008) 'Business justification with business intelligence', VINE. doi:

$10.1108 / 03055720810917714$.

Saxena, R. and Srinivasan, A. (2013) 'Business intelligence', in International Series in Operations Research and Management Science. doi: 10.1007/978-1-4614-6080-0_7.

Shariat, M. and Hightower Jr, R. (2007) 'Conceptualizing business intelligence architecture.', Marketing Management Journal.

Sircar, S. (2009) 'Business intelligence in the business curriculum', Communications of the Association for Information Systems. doi: 10.17705/1cais.02417.

Tucker, M. L., Gullekson, N. L. and Esmond-kiger, C. (2014) 'Accounting for EI : Does emotional intelligence predict greater intercultural growth?', Journal of International Buisness and Cultural Studies.

West, A., Clifford, J. and Atkinson, D. (2018) “"Alexa, build me a brand” An Investigation into the impact of Artificial Intelligence on Branding', The Business and Management Review.

Williams, S. and Williams, N. (2007) The Profit Impact of Business Intelligence, The Profit Impact of Business Intelligence. doi: 10.1016/B978-0-12-372499-1.X5000-5. 